\title{
Double Diode Ideality Factor Determination using the Fixed-Point Method
}

\author{
Traiki Ghizlane ${ }^{1}$, Ouajji Hassan², Bifadene Abdelkader ${ }^{3}$, Bouattane Omar ${ }^{4}$ \\ Laboratory of Signals, Distributed Systems and Intelligence Artificial \\ ENSET Mohammedia, HASSAN II University Casablanca,Morocco
}

\begin{abstract}
In this paper, we are interested in the diode ideality factor study of the double exponential equivalent model, based on the properties of the fixed point method. The optimal choice of this factor will improve the photovoltaic installation profitability. The diode ideality factor is a crucial parameter to describe solar cell behavior. Different methods have been elaborated to determine its value; some of them are analytical as Lambert function and others are direct as the normal method of the coordinates of the parameters. In our case, we applied the fixed point method which is an iterative algorithm to solve non-linear equations. The values obtained by this method are compared with the calculated values achieved by other methods to prove its significance and effects.
\end{abstract}

Keywords-Ideality factor; fixed point; double diode; solar cell

\section{INTRODUCTION}

The solar cell mathematical modeling is a crucial and indispensable step for the photovoltaic generator performance study and any optimization operation. Mostly the photovoltaic cell is represented by an equivalent electrical circuit whose parameters are based on the current-voltage characteristic. In this context, several methods have been investigated to determine the equivalent circuit parameters mentioned above. The diode ideality factor is an important parameter in the electrical behavior description of the $\mathrm{p}-\mathrm{n}$ junction solar cell. This empirical factor indicates the material quality; it is due to the atomic interaction of the semiconductor-metal interface. It reports excess recombination in the depletion zone [1], [2]. This factor depends on the operating conditions of the device. In the case of minority carrier scattering, the Shockley scattering theory gives approximately the value of the ideality factor of the diode between 1 and 2 for silicon diodes in the case of recombination in the charge region of space [1, 2]. Theories have predicted $n=2$ at high injection levels as the recombination density increases $[3,4]$. The increase in the quality factor of the diode affects the quality of the diode and the point of maximum power in the operating area. The diode ideality factor depends on weather conditions such as temperature, lighting and also voltage [5]. Several methods have been developed to extract the value of the diode ideality factor based on the exponential diode model, which explains the introduction of different values of the diode ideality factor from direct methods such as direct measurement [6], the method of the series of variable resistances [7], the normal method of the coordinates of the parameters [8, 9]. Other analytical methods have been developed such as the techniques for determining the diode ideality factor of solar cells were given in [8] [9] and special transfusion theory (STFT), which is a tool for solving transcendental equations [10-14], solutions based on this method are accurate and analytical. However, the exponential diode model is considered insufficient to correctly describe the two linear regions of the voltage-current characteristic of the photovoltaic cell; so we consider the twoexponential model to figure out this problem as in [15]. The main objective of this study is to propose another method to determine the value of the diode ideality factor (n) using a fixed-point iterative method that is applied to solve non-linear equations. This method is applied to the double exponential mathematical model given in equation (1). Recently, there is strong competition in the field of photovoltaic panels manufacture, we determine an optimal value of diode ideality factor which represents the diode conformity to a pure thermoconduction to improve the process Manufacturing.

This paper is split into four parts: Section 2 is a presents the fixed-point method and its applications to our case of a double diode solar cell. Section 3 shows some simulation results and discussion to determine factor ideality of a grey solar cell studied in [5]. The final section gives some concluding remarks.

\section{FIXED POINT METHOD}

\section{A. Presentation}

The fixed point method is a numerical technique; it has been used to solve the problems of nonlinear equations and implicit functions. This method has been cited in several fields such as chemistry and biology as well as others, the simplicity and usefulness of this method have prompted many researchers to extend it further.

The iterative process is a crucial principle in computer science. It is principally used to find equations roots, solutions of nonlinear equations and differential equations, and so.

The fixed-point method generally devoted to solve nonlinear equations expressed as $\mathrm{y}(\mathrm{x})=0$, where $\mathrm{y}$ is a nonlinear function of a variable $\mathrm{x}$. The method is based on an iterative scheme to lead a given convergent sequence towards a fixed point $\mathrm{x}$ of its corresponding function, this fixed point is the solution of the equation $\mathrm{y}(\mathrm{x})=0$.

This method is defined as follows:

- Convert the equation $y(x)=0$ into the form $x=F(x)$.

- Elaborate an iterative procedure to implement the corresponding sequence. 
- Start with an initial guess $\mathrm{x}_{0} \approx \mathrm{r}$, where $\mathrm{r}$ is the initial solution of the equation.

- Iterate the procedure $x_{n+1}:=F\left(x_{n}\right)$ for any index $n$.

A Fixed-point technique is one of the methods to figure out nonlinear equations. As an example of the complex nonlinear equations translating some physical behavior, the one studied in [16]. In our case of the exploitation of the totality of the current-voltage measurements coming directly from a PV module, we analyze the equation (1) to solve it using the fixedpoint method to pick out the diode ideality factor of the solar cell component.

In this paper, we propose a fixed-point method to solve the nonlinear equation (1). Since, others seem to be more complicate to implement directly. As an example, we find those used in "STFT" [6] and "W-function" [10, 17].

\section{B. Application to the Solar Cell Model}

In this work, the fixed-point method is used to solve the nonlinear equation of the double exponential electric model of Fig. 1. The model has seven parameters $\left(I_{\mathrm{ph}}, \mathrm{I}_{01}, \mathrm{I}_{02}, \mathrm{n}_{1}, \mathrm{n}_{2}, \mathrm{R}_{\mathrm{s}}\right.$ and $\left.R_{\text {sh }}\right)$. This method has shown its efficiency and interesting performances in different disciplines. As an example; it was used to calculate the two-dimensional magnetic field in a device with magnetic hysteresis that was modeled by a simple analytical scalar model. This approach allowed easily the computation convergence [18].

The seven parameters knowledge allow controlling the solar cell performance and make the maximum power point (MPP) extraction enabled in the photovoltaic generator.

Therefore, the identification of the photovoltaic cell parameters is a crucial step for the photovoltaic generator performance study and output optimization. Unfortunately, equation (1) is an implicit transcendental nonlinear equation. This implicit form increases the complexity of parameter extraction and PV systems. To solve this equation, we propose an iterative approach to find the roots and solutions of this nonlinear equation.

The double junction photovoltaic cell model represents more closely the observable effects on the device under various lighting conditions.

The solar cell electrical behavior, represented by two diodes, is described by the equation (1) [5]:

$I=I_{p h}-I_{01}\left(e^{\frac{V+R_{S} I}{n_{1} V_{t n}}}-1\right)-I_{02}\left(e^{\frac{V+R_{s} I}{n_{2} V_{t n}}}-1\right)-\frac{V+R_{S} I}{R_{s h}}$



Fig. 1. Equivalent Electrical Model of the Double Junction Photovoltaic Cell.
Where:

- The thermal voltage is:

$\mathrm{V}_{\mathrm{tn}}=\mathrm{KT} / \mathrm{q}$

- $\mathrm{I}_{01}, \mathrm{I}_{02}$ : saturation current in the diodes $\mathrm{D}_{1}$ and $\mathrm{D}_{2}$.

- $\mathrm{n}_{1}, \mathrm{n}_{2}$ : the junction ideality factor.

- I: supplied current by the cell when it operates as a generator.

- $\mathrm{V}_{\mathrm{tn}}$ : voltage at the terminals of a cell.

- $\mathrm{I}_{\mathrm{ph}}$ : the cell photo-current; it depends on the illumination and the temperature.

- $\mathrm{R}_{\mathrm{sh}}$ : shunt resistance characterizing the junction leakage currents.

- $\mathrm{R}_{\mathrm{s}}$ : series resistor representing the various contacts and connections resistances.

- $\mathrm{K}$ : Boltzmann constant (1.381 $\left.10^{-23} \mathrm{~J} / \mathrm{K}\right)$.

- T: cells effective temperature in Kelvin $\left({ }^{\circ} \mathrm{K}\right)$.

- $\mathrm{q}$ : the electron charge $\left(\mathrm{q}=1.610^{-19} \mathrm{C}\right)$.

The fixed-point method consists of elaborating an iterative scheme, in this case, a convergent sequence toward a fixed point $\mathrm{x}$ of equation (3), this fixed point is the solution of the equation (1).

According to the notation taken at the fixed-point method, the equation (1) can be rewritten as:

$\mathrm{y}(\mathrm{I})=\mathrm{I}-\mathrm{F}(\mathrm{I})$

The function $\mathrm{F}$ (I) means:

$F(I)=I_{p h}-I_{01}\left(e^{\frac{V+R_{S} I}{n_{1} V_{t n}}}-1\right)-I_{02}\left(e^{\frac{V+R_{S} I}{n_{2} V_{t n}}}-1\right)-\frac{V+R_{S} I}{R_{s h}}$

The current value $\mathrm{I}$ is in the range as: $-0.5<\mathrm{I}<2.5$.

The proposed method is implemented using the wellknown model of the grey solar cell parameters as in [5]. Table I presents these parameters.

We used data of Charles et al and Phang et al [5] [17] to evaluate different parameters for two solar cells, namely, grey solar cell (Table I).

TABLE. I. The PARAmeters of The SOlar Cell "GreY" ObTAined FROM [5], [17]

\begin{tabular}{|l|l|}
\hline Parameter & Grey solar cell \\
\hline $\mathrm{V}_{\mathrm{oc}}(\mathrm{V})$ & 0.524 \\
\hline $\mathrm{R}_{\mathrm{s}}(\Omega)$ & 0.036740 \\
\hline $\mathrm{R}_{\mathrm{sh}}(\Omega)$ & 55.485443 \\
\hline $\mathrm{I}_{01}(\mu \mathrm{A})$ & 0.225974 \\
\hline $\mathrm{I}_{02}(\mu \mathrm{A})$ & 0.749347 \\
\hline $\mathrm{I}_{\mathrm{ph}}(\mathrm{A})$ & 0.760781 \\
\hline $\mathrm{V}_{\text {th }}(\mathrm{mV})$ & 26.479 \\
\hline
\end{tabular}




\section{Determination Diode Ideality Factor Optimal Value}

Further to this, the diode ideality factors determination is giving according to the following steps:

To determine the optimal value of diode ideality factor, we use an iterative process and look for the corresponding meeting point $\mathrm{I}=\mathrm{F}(\mathrm{I})$ for different curves of diode ideality factors values. This meeting point represents the optimal solution of the nonlinear equations (1).

The implementation process to determine the diode ideality factors we set the problem as:

- Find the point meeting $\mathrm{I}=\mathrm{F}(\mathrm{I})$ for different values of $\mathrm{n}_{1}$ and $\mathrm{n}_{2}$.

- Using an iterative process, Fig. 3 shows the corresponding curve for each value of $n_{1}$ and $n_{2}$. The intersection $\mathrm{I}$ and $\mathrm{F}(\mathrm{I})$ around the point $(0,0)$ is the solution of a particular diode ideality factors we are looking for.

a) Algorithm of diode ideality factor value determination using fixed point method:

- Define initialize conditions:

$\mathrm{n}_{01}, \mathrm{n}_{02}, \Delta \mathrm{n}$

- Initialize parameters:

$\mathrm{n}_{01}=1$ and $\mathrm{n}_{02}=1$

- Start loop

While the meeting point is different to 0

Increment $\mathrm{n}_{1}$ and $\mathrm{n}_{2}$

Update $\mathrm{n}_{1}$ and $\mathrm{n}_{2}$

Compute $\mathrm{y}=\mathrm{I}+\mathrm{F}(\mathrm{I})$

Repeat the loop until equal " 0 "

- Result: the final " $\mathrm{n}_{1}$ and $\mathrm{n}_{2}$ " present the real value.

In this work, the fixed point method has been represented by a nested loop of complexity $\mathrm{O}\left(\mathrm{n}^{2}\right)$.

Fig. 2 shows the evolution of the function y according to different values of diode ideality factor.

The graph of $\mathrm{f}(\mathrm{I})$, shown in Fig. 3, crosses the graph of $\mathrm{f}(\mathrm{I})=\mathrm{I}$ at different factors ideality values. The point $(0,0)$ is the solution to equation (1).

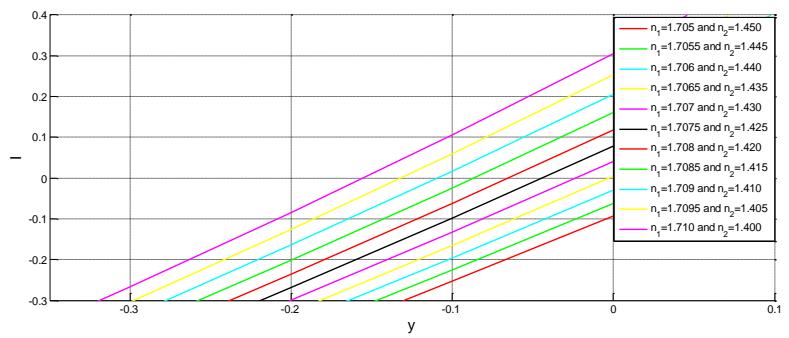

Fig. 2. Evolution of $\mathrm{y}(\mathrm{I})=\mathrm{I}-\mathrm{f}(\mathrm{I})$ for a Variable Diode Ideality Factor.

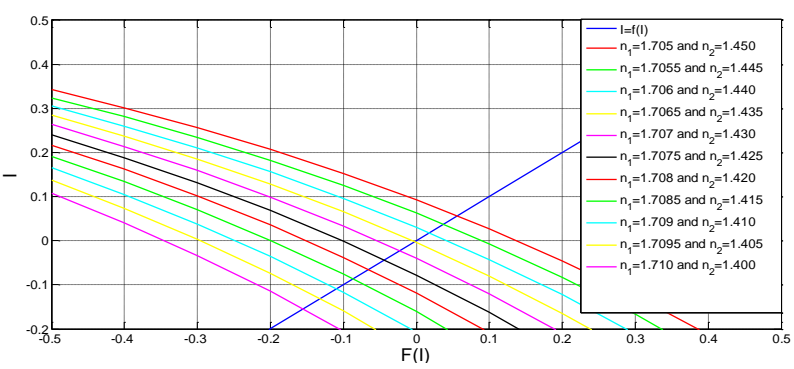

Fig. 3. Evolution of $\mathrm{f}(\mathrm{I})=\mathrm{I}$ for a Various Diode Ideality Factor.

It requires extensive calculation and good approximations, which ensure the convergence of iterations. This method gives an explicit solution to the current-voltage equation (1) of the solar cell. Fig. 3 illustrates the different current-voltage characteristics of a gray solar cell for different diode ideality factors (small variations). We notify that the current depends on the diode ideality factor since the current increases gradually as the diode ideality factor decreases. The equation (1) solution converges to point $\mathrm{I}-\mathrm{F}(\mathrm{I})=0$ for two diode ideality factors of the double junction photovoltaic cell $\mathrm{n}_{1}=1.7065$ and $\mathrm{n}_{2}=1.435$.

\section{RESULTS AND DISCUSSION}

This section is devoted to discussing the obtained results compared with some related ones in the literature. This comparison concerns both performances of the solar cells and those of the solar modules.

\section{A. Performance Comparison for Solar Cell}

In order to evaluate the performance of the proposed method, the solar cell diode ideality factor extraction simulations and analysis were carried out for the different algorithms mentioned above as well as the fixed-point method. The comparisons operate on the parameter set values and absolute error.

For the algorithms named teaching-learning-based optimization, (TLBO) and simple teaching-learning-based optimization (STLBO) [19] were used to determine the unknown parameters in the nonlinear solar cell models since they are assigned for constrained mechanical design optimization problems. This technique is distinguished by fewer adjustable parameters. In [20], biogeography-based optimization (BBO) was used to find the optimal estimation parameters of both solar and fuel cells. BBO algorithm includes the mutation motivated from the differential evolution (DE) algorithm [21]; it gives solutions of high quality and has a fast convergence rate. In [22], the method applied is pattern Search (PS) that can divine a wide range of optimization problems. This technique minimizes the error associated with the estimated solar cell parameters. The technique applied in [13] uses a meta-heuristic approach for optimization, which is the particle swarm optimization (PSO) the algorithm that has a higher expectation to determine a global solution in comparison with deterministic ones.

The parameter values listed in Table II are represented in Fig. 4 to show the different results of different authors to solve the solar cell equation. The I-V experimental data has been 
used by these algorithms for parameter extraction of the double diode model of equation (1).

Table II represents the calculated values compared to diode ideality factors obtained from different analytical and iterative methods.

According to Table II and Fig. 4, there is a correlation between the values of the diode ideality factors $\left(n_{1}\right.$ and $\left.n_{2}\right)$ obtained from the different algorithms and those obtained from the fixed point method since the values calculated using the proposed method are close to those of the algorithms listed in the table.

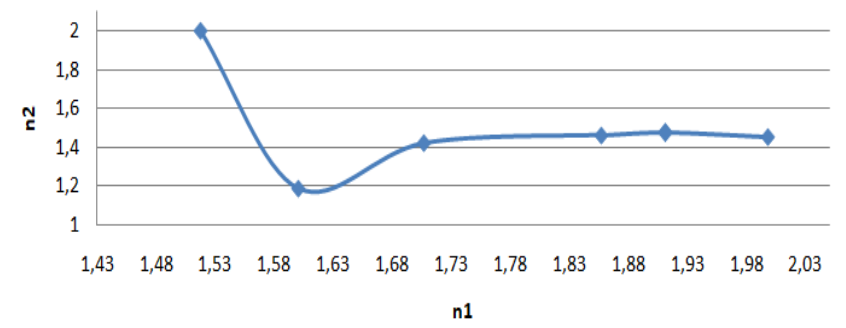

Fig. 4. Representation of Diode Ideality Factors $\left(n_{1}, n_{2}\right)$ Values Extracted from different Algorithms.

TABLE. II. THE VALUES OF THE IDEALITY FACTORS OF THE DOUBLE-EXPONENTIAL SOLAR CELL EXTRACTED BY DIFFERENT ALGORITHMS

\begin{tabular}{|c|c|c|c|c|c|c|c|c|}
\hline $\begin{array}{l}\text { Algorithms / } \\
\text { methods }\end{array}$ & $\mathbf{I}_{\mathrm{ph}}(\mathbf{A})$ & $\mathbf{I}_{01}(\boldsymbol{\mu} \mathbf{A})$ & $\mathbf{I}_{02}(\boldsymbol{\mu A})$ & $\mathbf{n}_{1}$ & $\mathbf{n}_{2}$ & $\mathbf{R}_{\mathrm{s}}(\mathbf{\Omega})$ & $\mathbf{R}_{\text {sh }}(\Omega)$ & RMSE \\
\hline $\begin{array}{l}\text { Fixed point } \\
\text { method }\end{array}$ & 0.760781 & 0.225974 & 0.749347 & 1.70650 & 1.43500 & 0.036740 & 55.485443 & $1.7084 \mathrm{e}^{-4}$ \\
\hline TLBO [19] & 0.76067 & 0.20289 & 0.29948 & 1.99809 & 1.47494 & 0.03646 & 55.8459 & $9.9507 \mathrm{e}^{-4}$ \\
\hline STLBO [19] & 0.76078 & 0.22566 & 0.75217 & 1.45085 & 2.00000 & 0.03674 & 55.4920 & $9.8248 \mathrm{e}^{-4}$ \\
\hline $\mathrm{DE}[20]$ & 0.76079 & 0.36605 & 0.26320 & 1.91164 & 1.46500 & 0.03661 & 56.0213 & $1 \mathrm{e}^{-3}$ \\
\hline BBO [20] & 0.75940 & 0.95830 & 0.14885 & 1.85714 & 1.42309 & 0.03673 & 58.4585 & $1.6 \mathrm{e}^{-3}$ \\
\hline PS [14] & 0.7602 & 0.9889 & 0.0001 & 1.6000 & 1.1920 & 0.0320 & 81.3008 & $1.517 \mathrm{e}^{-2}$ \\
\hline PSO [13] & 0.7623 & 0.4767 & 0.0100 & 1.5172 & 2.0000 & 0.0325 & 43.1034 & $1.66 \mathrm{e}^{-3}$ \\
\hline Rcr-IJADE [23] & 0.760781 & 0.225974 & 0.749347 & 1.451017 & 2.00000 & 0.036740 & 55.485443 & $9.8602 \mathrm{e}^{-4}$ \\
\hline CSO [24] & 0.76078 & 0.22732 & 0.72785 & 1.45151 & 1.99769 & 0.036737 & 55.3813 & $9.8252 \mathrm{e}^{-4}$ \\
\hline BMO [25] & 0.76078 & 0.21110 & 0.87688 & 1.44533 & 1.99997 & 0.03682 & 55.8081 & $9.8262 \mathrm{e}^{-4}$ \\
\hline GOTLBO [26] & 0.760752 & 0.800195 & 0.220462 & 1.999973 & 1.448974 & 0.036783 & 56.075304 & $9.83177 \mathrm{e}^{-4}$ \\
\hline ABSO [27] & 0.76078 & 0.26713 & 0.38191 & 1.46512 & 1.98152 & 0.03657 & 54.6219 & $9.8344 \mathrm{e}^{-4}$ \\
\hline IGHS [28] & 0.76079 & 0.97310 & 0.16791 & 1.92126 & 1.42814 & 0.03690 & 56.8368 & $9.8635 \mathrm{e}^{-4}$ \\
\hline BBO-M [20] & 0.76083 & 0.59115 & 0.24523 & 2.00000 & 1.45798 & 0.03664 & 55.0494 & $9.8272 \mathrm{e}^{-4}$ \\
\hline GGHS [28] & 0.76056 & 0.37014 & 0.13504 & 1.49638 & 1.92998 & 0.03562 & 62.7899 & $9.9097 \mathrm{e}^{-4}$ \\
\hline FPA [29] & 0.760795 & 0.300088 & 0.166159 & 1.47477 & 2.0000 & 0.0363342 & 52.3475 & $7.7301 \mathrm{e}^{-4}$ \\
\hline HS [28] & 0.76176 & 0.12545 & 0.25470 & 1.49439 & 1.49989 & 0.03545 & 46.82696 & $9.9510 \mathrm{e}^{-4}$ \\
\hline MPCOA [30] & 0.76078 & 0.31259 & 0.04528 & 1.47844 & 1.78549 & 0.03635 & 54.2531 & $9.4457 \mathrm{e}^{-4}$ \\
\hline CARO [31] & 0.76075 & 0.29315 & 0.09098 & 1.47338 & 1.77321 & 0.03641 & 54.3967 & $9.8260 \mathrm{e}^{-4}$ \\
\hline $\mathrm{ABC}[32]$ & 0.7608 & 0.0407 & 0.2847 & 1.4495 & 1.4885 & 0.0364 & 53.7804 & $9.861 \mathrm{e}^{-4}$ \\
\hline DE [33] & 0.76078 & 0.22599 & 0.75438 & 1.44972 & 1.99999 & 0.03674 & 55.4922 & $9.8246 \mathrm{e}^{-4}$ \\
\hline ABSO [33] & 0.76078 & 0.22599 & 0.75439 & 1.44972 & 1.99999 & 0.03674 & 55.4922 & $9.8246 \mathrm{e}^{-4}$ \\
\hline ABCDE [33] & 0.76078 & 0.22599 & 0.75437 & 1.44972 & 1.99998 & 0.03674 & 55.4921 & $9.8246 \mathrm{e}^{-4}$ \\
\hline
\end{tabular}


The root means square error (RMSE) is used to quantify the difference between the calculated and the experimental currents. However, although the RMSE is smaller, the calculated values are more adequacies to the experimental $\mathrm{I}-\mathrm{V}$ data of solar cells.

It is defined by:

$\mathrm{RMSE}=\sqrt{\frac{1}{N} \sum_{i=1}^{N}\left(I_{\text {calculated }}-I_{\text {experimental }}\right)^{2}}$

Where $\mathrm{N}$ is the number of experimental $\mathrm{I}-\mathrm{V}$ data of a 57 $\mathrm{mm}$ diameter commercial silicon solar cell from the system under $1000 \mathrm{~W} / \mathrm{m}^{2}$ at $33^{\circ} \mathrm{C}$ [34], which is represented in Table IV.

The RMSE value provided by the fixed-point method is $1.7084 \mathrm{e}^{-4}$ as illustrated in Table II. It represents one of the low values.

To ensure an objective study of the fixed-point method and different algorithms in the next section, the calculated values and experimental $\mathrm{I}-\mathrm{V}$ data of solar cell and the solar module were simulated.

Fig. 5 and 6 are a plot of the calculated value of current versus voltage and the power versus voltage. These figures show the effects of diode ideality factor variation (extracted from the different algorithm) on the I-V and P-V characteristics, the factor extracted from the fixed point method increased the voltage and the maximum power values.

a) Absolute Current Error (ACE): The absolute current error (ACE), which is defined as the absolute value of the difference between the calculated current and the measured current, is defined by equation 6 . It used to show the performance and the robustness of the algorithm.

$\mathrm{ACE}=\left|I_{\text {calculated }, i}-I_{\text {experimental }, i}\right|$

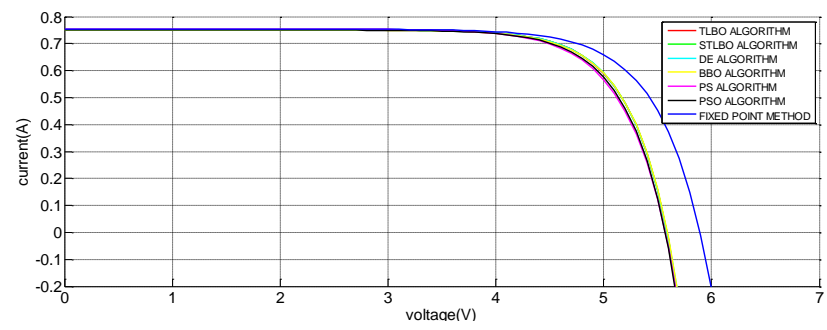

Fig. 5. Current-Voltage of Parameters Values Extracted from Several Algorithms.

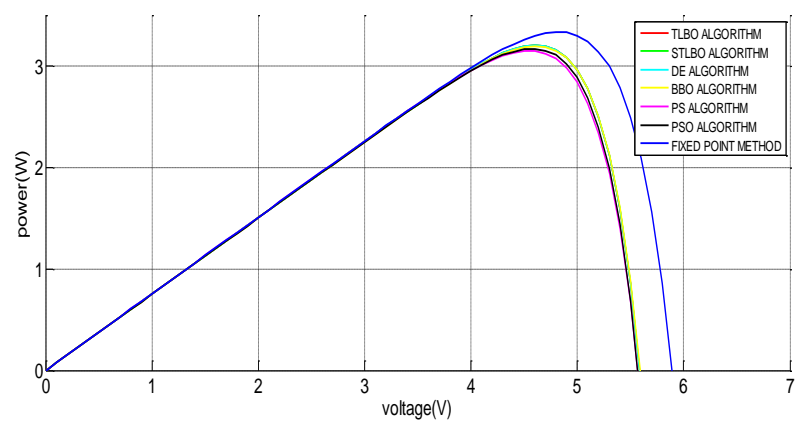

Fig. 6. Power-Voltage of Parameters Values Extracted from Several Algorithms.
The absolute current error sum is calculated in Table III.

Fig. 7 is a plot of the variation of absolute current error for a different method. At $0.3873 \mathrm{~V}$, most of the algorithm achieves their maximum.

However, the fixed-point method and the BBO algorithm have almost the same absolute current error variation; its performance is chosen to be compared to the performance of the fixed-point method in Table IV.

Table IV summarizes the ACE value for fixed-point method and BBO algorithm based on the experimental I-V data. The fixed point RMSE value is $7,77166 \mathrm{e}^{-6}$ and for BBO is $1,10 \mathrm{e}^{-5}$.

The experimental current value is different from the one of the current calculated in Table IV.

The simulated I-V characteristics of the fixed-point method as well as the BBO algorithm and their absolute current errors for each data point are shown in Fig. 8, 9 and 10, respectively.

The parameter simulation extracted from BBO algorithm for R.T.C France solar cell yields $3.5 \mathrm{~W}$ as a maximum power point and for the fixed point method, the peak of the powervoltage curve is $3.6 \mathrm{w}$.

The absolute current simulation indicate that the results of the fixed-point method coincide with the BBO algorithm data both in a double diode model, which means that the extracted parameters are very accurate.

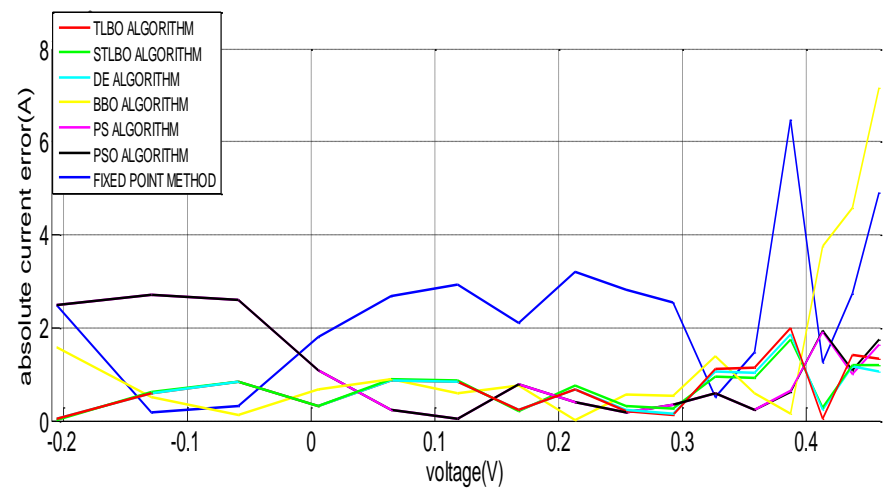

Fig. 7. Absolute Current Error of different Analytical and Iterative Methods.

TABLE. III. CAlCUlated AbSOlute CURRENT ERROR FOR Double DIODE MODEL

\begin{tabular}{|l|l|}
\hline Algorithms / methods & ACE \\
\hline Fixed point method & $3,84 \mathrm{e}^{-2}$ \\
\hline TLBO [19] & $1,31 \mathrm{e}^{-2}$ \\
\hline STLBO [19] & $1,25 \mathrm{e}^{-2}$ \\
\hline DE [20] & $1,22 \mathrm{e}^{-2}$ \\
\hline BBO [20] & $3,35 \mathrm{e}^{-2}$ \\
\hline PS [22] & $1,92 \mathrm{e}^{-2}$ \\
\hline PSO [13] & $1,71 \mathrm{e}^{-2}$ \\
\hline
\end{tabular}




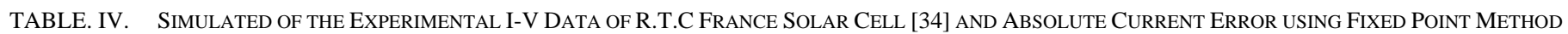

\begin{tabular}{|c|c|c|c|c|c|c|}
\hline \multirow{2}{*}{ Items $(\mathbf{N})$} & \multicolumn{2}{|c|}{ Experimental data } & \multicolumn{2}{|l|}{ Fixed point method } & \multicolumn{2}{|l|}{ BBO algorithm } \\
\hline & Voltage(V) & Current (A) & Calculated current(A) & $\operatorname{ACE}(A)$ & Calculated current(A) & $\operatorname{ACE}(A)$ \\
\hline 1 & $-0,2057$ & 0,764 & 0,76649666 & 0,00249666 & 0,76243038 & 0,00156962 \\
\hline 2 & $-0,1291$ & 0,762 & 0,76182101 & 0,00017899 & 0,76148891 & 0,00051109 \\
\hline 3 & $-0,0588$ & 0,7605 & 0,76019100 & 0,00030900 & 0,76062446 & 0,00012446 \\
\hline 4 & 0,0057 & 0,7605 & 0,75869387 & 0,00180613 & 0,75982953 & 0,00067047 \\
\hline 5 & 0,0646 & 0,76 & 0,75732517 & 0,00267483 & 0,75909917 & 0,00090083 \\
\hline 6 & 0,1185 & 0,759 & 0,75606716 & 0,00293284 & 0,75841572 & 0,00058428 \\
\hline 7 & 0,1678 & 0,757 & 0,75490117 & 0,00209883 & 0,75774623 & 0,00074623 \\
\hline 8 & 0,2132 & 0,757 & 0,75378517 & 0,00321483 & 0,75700885 & $8,8545 \mathrm{E}-06$ \\
\hline 9 & 0,2545 & 0,7555 & 0,75267857 & 0,00282143 & 0,75605193 & 0,00055193 \\
\hline 10 & 0,2924 & 0,754 & 0,75146821 & 0,00253179 & 0,75454122 & 0,00054122 \\
\hline 11 & 0,3269 & 0,7505 & 0,74999282 & 0,00050718 & 0,75189884 & 0,00139884 \\
\hline 12 & 0,3585 & 0,7465 & 0,74796312 & 0,00146312 & 0,74710255 & 0,00060255 \\
\hline 13 & 0,3873 & 0,7385 & 0,74498473 & 0,00148473 & 0,73864665 & 0,00014665 \\
\hline 14 & 0,4137 & 0,728 & 0,74046200 & 0,00124620 & 0,72424173 & 0,00375827 \\
\hline 15 & 0,4373 & 0,7065 & 0,73394175 & 0,00274417 & 0,70192341 & 0,00457659 \\
\hline 16 & 0,459 & 0,6755 & 0,72458677 & 0,00490868 & 0,66834844 & 0,00715156 \\
\hline
\end{tabular}

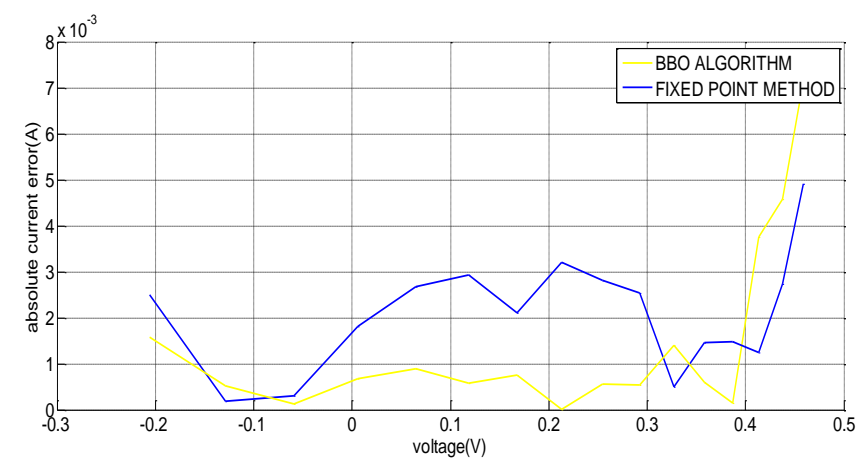

Fig. 8. Absolute Current Error Variation of Fixed Point Method and BBO Algorithm.



Fig. 9. Power-Voltage of Fixed Point Method and BBO Algorithm.

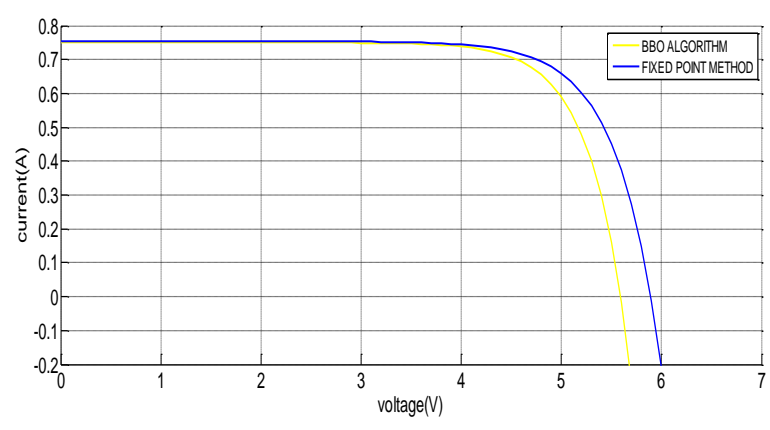

Fig. 10. Current-Voltage of Fixed Point Method and BBO Algorithm.

\section{B. Performance Comparison Results for Solar Module}

The fixed point method is evaluated using the reported parameter values extracted from FPA and experimental I-V data of solar module from mono-crystalline (SM55) [23]. The number of cells in series in this solar module is 36. The reported parameter values of the SM55 module are mentioned respectively in Tables $\mathrm{V}$ and VI.

It is essential to understand the effect of changing a solar cell temperature on the characteristic $\mathrm{I}=\mathrm{f}(\mathrm{V})$ (Fig. 11 and 12), The current depends on the temperature since the current increases slightly as the temperature increases, but the temperature has a negative influence on the open-circuit voltage. When the temperature increases the open-circuit voltage decreases. Therefore the maximum power decreased. 
TABLE. V. THE EXTRACTED PARAMETERS FOR MONO-CRYSTALLINE SM55 PV MODULE BY FPA AT DIFFERENT TEMPERATURE AND IRRADIATION OF 1000 W/M² (DOUBLE DiODE MODEL) [35]

\begin{tabular}{|l|l|l|l|l|l|l|l|}
\hline Temperature $\left({ }^{\circ} \mathbf{C}\right)$ & $\mathbf{I}_{\mathbf{p h}}(\mathbf{A})$ & $\mathbf{I}_{\mathbf{0 1}}(\boldsymbol{\mu \mathbf { A }})$ & $\mathbf{I}_{\mathbf{0 2}}(\boldsymbol{\mu} \mathbf{A})$ & $\mathbf{n}_{\mathbf{1}}$ & $\mathbf{n}_{\mathbf{2}}$ & $\mathbf{R}_{\mathbf{s}}(\mathbf{\Omega})$ \\
\hline 25 & 3.450253 & 0.1302402 & 0.359717 & 1.373022 & 2.114513 & 0.3392569 & 442.917 \\
\hline 40 & 3.467988 & 0.7258092 & 0.6681137 & 1.378014 & 3.896155 & 0.3389987 & 454.9449 \\
\hline 60 & 3.49099 & 5.24174 & 20.85424 & 1.378047 & 3.560465 & 0.338981 & 470.6224 \\
\hline
\end{tabular}

TABLE. VI. The EXTRACTED PARAMETERS FOR MONO-Crystalline SM55 PV MOdULE By FPA AT DiFFERENT IRRADIATION AND TEMPERATURE $25^{\circ} \mathrm{C}$ (DOUBLE Diode MODEL) [35]

\begin{tabular}{|c|c|c|c|c|c|c|c|}
\hline $\begin{array}{l}\text { Irradiation } \\
\left(\mathrm{W} / \mathbf{m}^{2}\right)\end{array}$ & $\begin{array}{l}\mathbf{I}_{\mathbf{p h}} \\
\text { (A) }\end{array}$ & $\begin{array}{l}\mathbf{I}_{01} \\
(\mu \mathbf{A})\end{array}$ & $\begin{array}{l}\mathbf{I}_{02} \\
(\mu \mathbf{A})\end{array}$ & $\mathbf{n}_{1}$ & $\mathbf{n}_{2}$ & $\begin{array}{l}\mathbf{R}_{\mathrm{s}} \\
(\mathbf{\Omega})\end{array}$ & $\begin{array}{l}\mathbf{R}_{\text {sh }} \\
(\Omega)\end{array}$ \\
\hline 200 & 0.6905771 & 0.1398725 & 0.1419069 & 1.378175 & 3.45683 & 0.3390007 & 443.4634 \\
\hline 400 & 1.380696 & 0.1392189 & 0.1215212 & 1.377924 & 2.297263 & 0.3386843 & 451.183 \\
\hline 600 & 2.068947 & 0.1472423 & 0.1530210 & 1.382451 & 2.834106 & 0.3380305 & 480.1678 \\
\hline 800 & 2.759354 & 0.1425452 & 0.6755132 & 1.379719 & 3.14591 & 0.3388229 & 469.336 \\
\hline 1000 & 3.450253 & 0.1302402 & 0.359717 & 1.373022 & 2.114513 & 0.3392569 & 442.917 \\
\hline
\end{tabular}

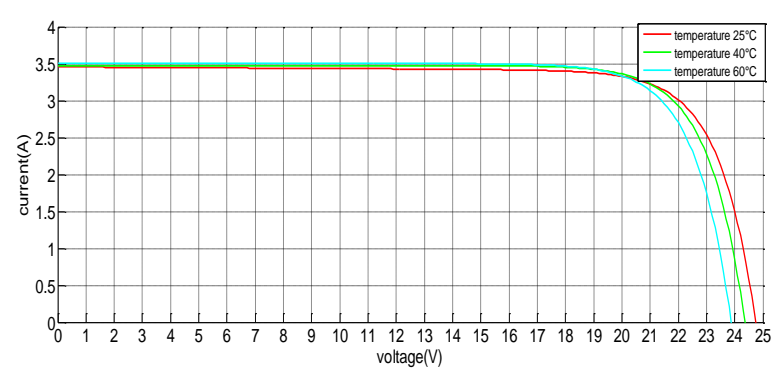

Fig. 11. Current-Voltage of SM55 PV Module for different Temperature.



Fig. 12. Power-Voltage of SM55 PV Module for different Temperature.



Fig. 13. Current-Voltage of SM55 PV Module for different Irradiation.
At a constant temperature (Fig. 13 and 14), it is found that the current undergoes a significant variation, but on the other hand, the tension varies slightly. Because the short circuitcurrent is a linear function of illumination while the opencircuit voltage is a logarithmic function.

In Fig. 15 and 16, the absolute current error in different radiation has the same variation as temperature. When the irradiation increases, the ACE increases, and decreases if the temperature increases.



Fig. 14. Power-Voltage of SM55 PV Module for different Irradiation.

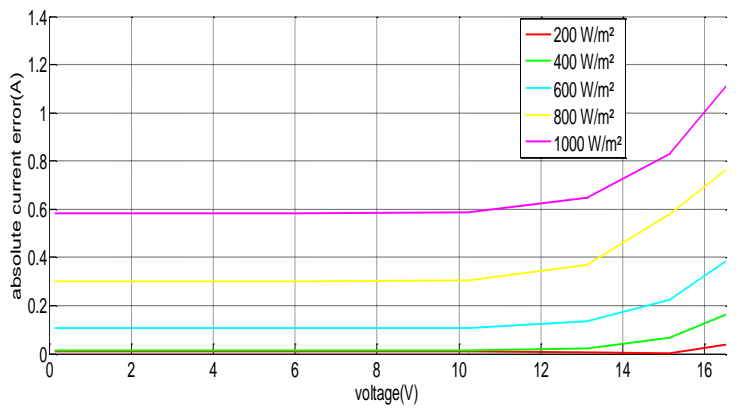

Fig. 15. Absolute Current Error of SM55 PV Module for different Irradiation. 


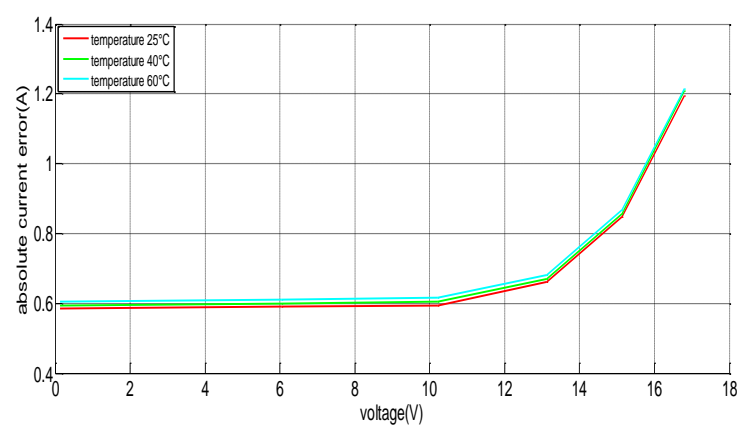

Fig. 16. Absolute Current Error of SM55 PV Module for different Temperature.

TABLE. VII. CAlculated RMSE of Double Diode Model For DIFFERENT IRRADIATIONS

\begin{tabular}{|l|l|l|}
\hline Irradiation $\left(\mathbf{w} / \mathbf{m}^{2}\right)$ & RMSE & $\begin{array}{l}\text { RMSE [5] } \\
\text { (Lambert } \mathbf{w} \text {-function) }\end{array}$ \\
\hline 200 & $1.85 \mathrm{e}^{-2}$ & $2.45 \mathrm{e}^{-2}$ \\
\hline 400 & $6.43 \mathrm{e}^{-2}$ & $2 \mathrm{e}^{-2}$ \\
\hline 600 & $2.02 \mathrm{e}^{-2}$ & $2.15 \mathrm{e}^{-2}$ \\
\hline 800 & $4.48 \mathrm{e}^{-21}$ & $4.24 \mathrm{e}^{-2}$ \\
\hline 1000 & $7.8 \mathrm{e}^{-2}$ & $5.77 \mathrm{e}^{-2}$ \\
\hline
\end{tabular}

TABLE. VIII. CALCUlATEd RMSE of Double Diode Model FoR DIFFERENT TEMPERATURE

\begin{tabular}{|l|l|l|}
\hline Temperature $\left({ }^{\circ} \mathbf{C}\right)$ & RMSE & $\begin{array}{l}\text { RMSE [5] (Lambert w- } \\
\text { function) }\end{array}$ \\
\hline 25 & $7.63 \mathrm{e}^{-2}$ & $5.77 \mathrm{e}^{-2}$ \\
\hline 40 & $7.72 \mathrm{e}^{-2}$ & $2.71 \mathrm{e}^{-2}$ \\
\hline 60 & $8.13 \mathrm{e}^{-2}$ & $2.09 \mathrm{e}^{-2}$ \\
\hline
\end{tabular}

a) Comparison the RMSE calculated using the method above with the one calculated using Lambert $w$-function: The simulation results on the double diode model are shown in Tables VII and VIII along with comparable results reported from Lambert W-function.

The RMSE values obtained is smaller and it coincides to the RMSE calculated using Lambert w-function

\section{CONCLUSION}

Most of the methods used to determine the diode ideality factor based on the solar cell simple diode model. As today there are several methods, it will be necessary to choose the appropriate methods in which the least approximations are made. The double diode model of characteristic I-V is the most appropriate model to understand the different physical phenomena occurring in each device region and to simulate adequately the operation of solar cells.

This paper presents a fixed point method based on double diode model of solar cells to extract the diode ideality factor values that solve nonlinear equations. The diode ideality factor values were found is close to extracted value by different algorithms.

We deduce from equation (1) and for a fixed temperature, the diode ideality factor decreases as the current increases. This factor varies depending on the semiconductor and the diode dimensions.

Moreover, the proposed methods allowed determining an approximate curve which will facilitate the extraction of the diode ideality factor $\left(\mathrm{n}_{1}\right.$ and $\left.\mathrm{n}_{2}\right)$ appropriate values.

The proposed method is compared to other similar algorithms in the literature such as BBO, PSO, PS, DE, TLBO, and STLBO. The algorithms and method efficiency has been evaluated in terms of accuracy.

The comparison of the fixed point method to other algorithms proved that there is a correlation between the optimal value of the ideality factors of the diode $n_{1}$ and $n_{2}$ defined by the fixed point method and those obtained from other techniques; so this method can be applied to a junction and multiple junctions.

\section{REFERENCES}

[1] Sze, S. M, "Semiconductor Devices: Physics and Technology. Technology", $2^{\text {nd }}$ Edition, 2006.

[2] M.Grundmann, "Including nanophysics and applications", $2^{\text {nd }}$ edition, Springer, 2010.

[3] Y.Chaibia, A.Allouhib, M.Malvonic, M.Salhia, R.Saadani, "Solar irradiance and temperature influence on the photovoltaic cell equivalentcircuit models", Solar Energy 188, 2019, pp. 1102-1110.

[4] F.Wang, X.Liu, F.Gao, "Fundamentals of solar cells and light-emitting diodes", Advanced Nanomaterials for Solar Cells and Light Emitting Diodes: in Micro and Nano Technologies , 2019.

[5] N.Santakrus Singh, A.Jain, A.Kapoor, "Determination of the solar cell junction ideality factor using special trans function theory (STFT)", Solar Energy Materials \& Solar Cells 93, 2009, pp. 1423-1426.

[6] M. Wolf, H. Rauschenbach, "Series resistance effects on solar cell measure- ments", Adv. Energy Convers. 3, 1963, pp. 455-479.

[7] P.Mialhe, J.Charette, "Experimental analysis of I-V characteristics of solar cells", Am.J.Phys.51, 1983, pp. 68-70.

[8] A. Jain, A. Kapoor, "A new method to determine the diode ideality factor of real solar cell using Lambert W-function", Solar Energy Materials and Solar Cells 85, 2005, pp. 391-396.

[9] P. Mialhe, J.P. Charles, A. Khoury, G. Bordure, "The diode quality factor of solar cells under illumination", J. Phys. D: Appl. Phys. 19,1986, pp. 483-492.

[10] S.M. Perovich, S.K. Simic, D.V. Tosic, S.I. Bauk, "On the analytical solution of some families of transcendental equations", Applied Mathematics Letters 20, 2007, pp. 493-498.

[11] S.M. Perovich, S. Bauk, I. Djurovic, "Calculating conductive fluid high level with special trans function theory", International Symposium on Electronics in Marine, 2004.

[12] S.M. Perovich, S. Bauk, R. Kulic, "The special trans function theory to the AM detector transfer factor analytical analysis", Ninth IEEE, ICECS, Croatia, Proc. ICECS, 2002, pp. 991-994.

[13] D.Oliva, E.Cuevas, G.Pajares, "Parameter identification of solar cells using artificial bee colony optimization”, Energy 72, 2014, pp. 93-102.

[14] MF.AlHajri, KM.El-Naggar, MR.AlRashidi, AK.Al-Othman, "Optimal extraction of solar cell parameters using pattern search", Renew Energy 44, 2012, pp. 238-45.

[15] N.Kavasoglu, A. Sertap Kavasoglu, S.Oktik, "A new method of diode ideality factor extraction from dark I-V curve", Current Applied Physics 9, 2009, pp. 833-838. 
[16] C.M. Singhal, "Analytical expression for the series resistance dependent maximum power point and curve factor for solar cells", Solar Cells 3, 1981, pp.163-177.

[17] X.Gao, Y.Cui, J.Hu, G.Xu, Y.Yu, "Lambert W-function based exact representation for double diode model of solar cells: comparison on fitness and parameter extraction", Energy Conversion and Management 127, 2016, pp. 443-460.

[18] N.Bello, A.Alkali, A.Roko, "A fixed point iterative method for the solution of two-point boundary value problems for second order differential", Equations Alexandria Engineering Journal , 2017.

[19] Q.Niu, H.Zhang, K.Li, "An improved TLBO with elite strategy for parameters identification of PEM fuel cell and solar cell models", International journal of hydrogen energy 39, 2014, pp.3837-3854.

[20] Q.Niu, L.Zhang, K.Li, “A biogeography-based optimization algorithm with mutation strategies for model parameter estimation of solar and fuel cells". Energy Convers Manage 86, 2014, pp. 1173-1185.

[21] D.Oliva, M.Abd Elaziz, A.H. Elsheikh, A.A.Ewees, "A review on metaheuristics methods for estimating parameters of solar cells", Journal of Power Sources, 2019.

[22] SM55module.www.solarquest.com/microsolar/suppliers/siemens/sm55. pdf.

[23] W.Gong, Z.Cai, "Parameter extraction of solar cell models using repaired adaptive differential evolution", Solar Energy 94, 2013,pp. 209-20.

[24] L.Guo, Z.Meng, Y.Sun, L.Wang, "Parameter identification and sensitivity analysis of solar cell models with cat swarm optimization algorithm", Energy Convers Manage 108, 2016,pp. 520-528.

[25] A.Askarzadeh, A.Rezazadeh, "Extraction of maximum power point in solar cells using bird mating optimizer-based parameters identification approach", Solar Energy 90, 2013, pp. 123-133.
[26] X.Chen, K.Yu, W.Du, W.Zhao, G.Liu, "Parameters identification of solar cell models using generalized oppositional teaching learning based optimization”, Energy 99, 2016, pp. 170-180.

[27] A.Askarzadeh, A.Rezazadeh, "Artificial bee swarm optimization algorithm for parameters identification of solar cell models". Applied Energy 102, 2013, pp. 943-949.

[28] A.Askarzadeh, A.Rezazadeh, "Parameter identification for solar cell models using harmony search-based algorithms", Solar Energy 86, 2012, pp. 3241-3249.

[29] DF.Alam, DA.Yousri, MB.Eteiba, "Flower pollination algorithm based solar PV parameter estimation", Energy Convers Manage 101, 2015, pp. 410-22.

[30] X.Yuan, Y.Xiang, Y.He, "Parameter extraction of solar cell models using mutative-scale parallel chaos optimization algorithm", Solar Energy 108, 2014, pp. 238-251.

[31] X.Yuan, Y.He, L.Liu, "Parameter extraction of solar cell models using chaotic asexual reproduction optimization", Neural Comput Appl 26, 2015, pp. 1227-1239.

[32] D.Oliva, E.Cuevas, G.Pajares, "Parameter identification of solar cells using artificial bee colony optimization", Energy 72, 2014, pp. 93-102.

[33] O.Hachana, KE.Hemsas, GM.Tina, C.Ventura, "Comparison of different metaheuristic algorithms for parameter identification of photovoltaic cell/module", Journal Renewable and Sustainable Energy 5, 2013, pp.053-122.

[34] T.Easwarakhanthan, J.Bottin, I.Bouhouch, C.Boutrit, "Nonlinear minimization algorithm for determining the solar cell parameters with microcomputers", Internationnal Journal of Solar Energy 4, 1986, pp. $1-12$.

[35] DF.Alam, DA .Yousri, MB.Eteiba, "Flower pollination algorithm based solar PV parameter estimation", Energy Conversion and Management 101, 2015, pp. 410-422. 